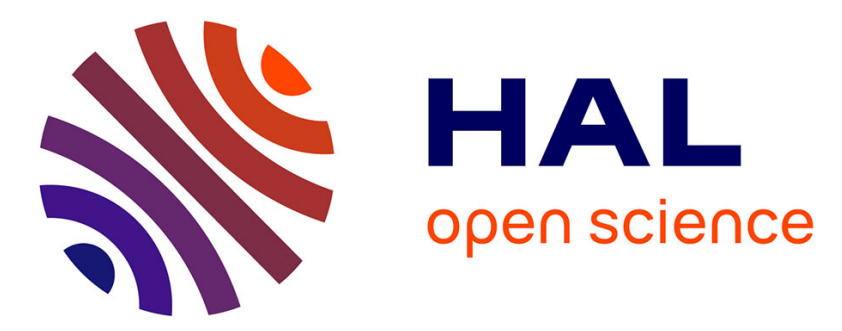

\title{
A worldwide-regionalised water supply mix (WSmix) for life cycle inventory of water use
}

Susana Leao, Philippe Roux, Montserrat Nunez, Eléonore Loiseau, Guillaume Junqua, Agata Sferratore, Ywann Penru, Ralph K. Rosenbaum

\section{To cite this version:}

Susana Leao, Philippe Roux, Montserrat Nunez, Eléonore Loiseau, Guillaume Junqua, et al.. A worldwide-regionalised water supply mix (WSmix) for life cycle inventory of water use. Journal of Cleaner Production, 2018, 172, pp.302-313. 10.1016/j.jclepro.2017.10.135 . hal-01870226

\section{HAL Id: hal-01870226 https://hal.science/hal-01870226}

Submitted on 7 Sep 2018

HAL is a multi-disciplinary open access archive for the deposit and dissemination of scientific research documents, whether they are published or not. The documents may come from teaching and research institutions in France or abroad, or from public or private research centers.
L'archive ouverte pluridisciplinaire HAL, est destinée au dépôt et à la diffusion de documents scientifiques de niveau recherche, publiés ou non, émanant des établissements d'enseignement et de recherche français ou étrangers, des laboratoires publics ou privés. 


\title{
Word account: 7514
}

2

\section{3}

4

\section{A worldwide-regionalised water supply mix (WSmix) for life cycle inventory of water use}

\author{
Susana Leão ${ }^{\text {a,b* }}$, Philippe Roux ${ }^{a}$, Montserrat Núñez a ${ }^{\text {, Eléonore Loiseau }}{ }^{\text {a }}$, Guillaume \\ Junqua $^{\text {b }}$, Agata Sferratore ${ }^{c}$, Ywann Penru ${ }^{d}$, Ralph K. Rosenbaum ${ }^{a}$ \\ ${ }^{\text {a }}$ ITAP, Irstea, Montpellier SupAgro, Univ Montpellier, ELSA Research group and ELSA-PACT Industrial \\ Chair, Montpellier, France

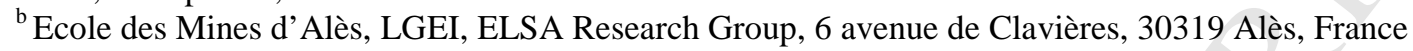 \\ ${ }^{\text {c }}$ Société du Canal de Provence, 966 Route de Pierrefeu, 83260 La Crau, Aix-en-Provence, France \\ ${ }^{\mathrm{d}}$ SUEZ Groupe 38, rue du Président Wilson 78230 Le Pecq, France \\ *Corresponding author. E-mail address: susana.de-oliveira-leao@irstea.fr
}

\section{Abstract}

Water utilities draw different water sources (surface and groundwater), including increased use of alternative sources (e.g. desalinated water, reused water, inter-basin water transfers) to supply freshwater to different users (domestic, agriculture, etc.). The combination of water sources and technologies (including infrastructures and energy) results in a regional water supply mix (WSmix) for each specific use. Existing Life Cycle Inventory (LCI) databases used in Life Cycle Assessment (LCA), do not include these mixes when modelling processes, leading to a poor representation of water supply systems and related environmental impacts.

To fill this gap, this paper proposes a consistent framework for modelling a regional WSmix at worldwide scale. The WSmix framework includes the scope and system boundaries definition as well as a standardisation of terminology and classification of water sources and users. To facilitate implementation of the WSmix, this paper provides a worldwide database of water source mixes per user and a technology matrix linking water sources to water production technologies, including the connection with the local electricity mix. 
31 The relevance of including the WSmix in LCI databases for proper water-use impact

32 assessment is demonstrated with an illustrative case study. The paper finally concludes on the

33 need of using the regionalized WSmix in routine LCA, which is just as straightforward as the

34 use of the regionalized electricity supply mix. Besides, the developed WSmix provides

35 interesting insights beyond the LCA scope to support the strategic management of water

36 sources at various scales including the global scale.

\section{Keywords}

\section{Abbreviations - Glossary}

$\begin{array}{ll}\text { GIS } & \text { Geographic Information System } \\ \text { LCA } & \text { Life Cycle Assessment } \\ \text { LCI } & \text { Life Cycle Inventory } \\ \text { LCIA } & \text { Life Cycle Impact Assessment } \\ \text { P } & \text { Precipitation } \\ \text { RB } & \text { River Basin } \\ \text { WE } & \text { Water Evaporation } \\ \text { WL } & \text { Water Losses } \\ \text { WP } & \text { Water Production } \\ \text { WO } & \text { Water sources } \\ \text { WOmix } & \text { Water source mix per user } \\ \text { WSmix } & \text { Water Supply mix } \\ \text { WU } & \text { Water Users } \\ \text { WTD } & \text { Water Treatment \& Distribution } \\ \text { WTec } & \text { Water Technologies } \\ \text { WTR } & \text { Water Transportation } \\ \text { WWTP } & \text { Waste Water Treatment Plant }\end{array}$




\section{Table of content}

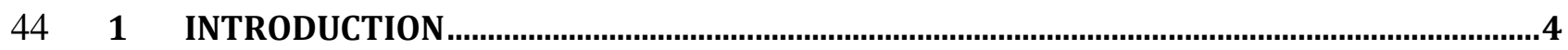

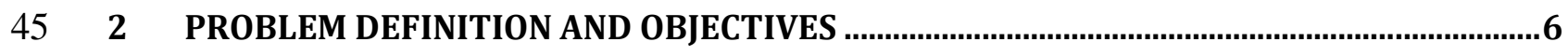

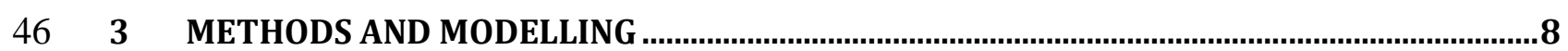

$47 \quad 3.1 \quad$ BASES OF THE WSMIX FRAMEWORK CONCEPT

$48 \quad 3.1 .1 \quad$ System definition and boundaries .................................................................................... 8

$49 \quad 3.1 .2$ Terminology and classification of the WSmix components ................................................ 9

$50 \quad 3.2$ WATER SOURCE MIX (WOMIX) DATABASE ……................................................................. 12

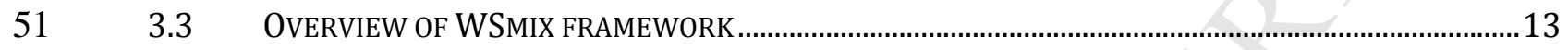

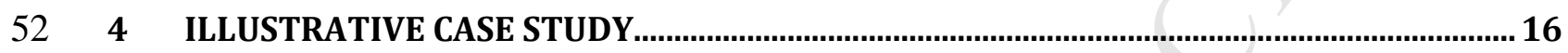

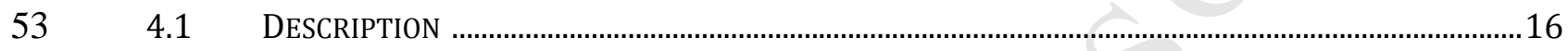

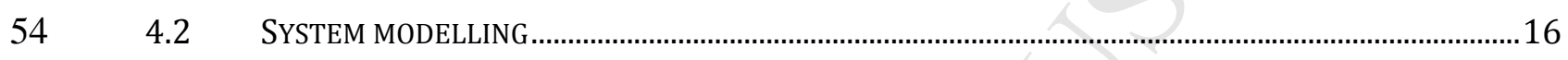

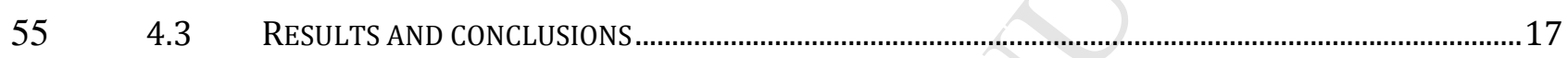

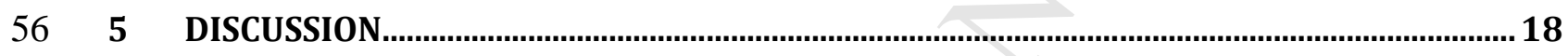

$57 \quad 5.1 \quad$ LIMITATIONS AND COMPLETENESS........................................................................................... 18

$58 \quad 5.2 \quad$ COMPATIBILITY AND REQUIREMENTS FOR IMPLEMENTATION IN LCA .............................................19

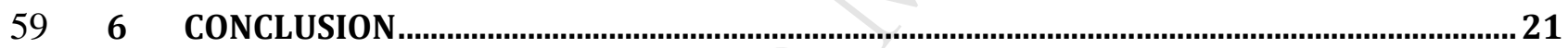

60 


\section{Introduction}

Water demand is increasing worldwide, especially due to population growth (FAO, 2011), while water availability in many regions is likely to decrease due to climate change and socioeconomic development patterns (WWDR4, 2012). The water variability in space, time and source has repercussions on the environment and on the management of water sources (Zhou et al., 2015).

Water utilities face a challenge to supply water to different users (domestic, agriculture, industry) during the entire year. They must address seasonal scarcity and human and ecosystem need fluctuations by combining different local conventional water sources (surface and groundwater), including increased use of alternative water sources, i.e. desalinated water, reused water, harvested rainwater (IWA, 2015a). In many cases, the water used by a specific user is coming from a mix of local and sometimes imported water sources rather than a single source (Hemmeter et al., 2016; IWA, 2015a). Depending on the origin of abstracted water, the geographical location (water abundant or scarce), the technologies used for water production (simple or advanced treatment, desalination, energy source, etc.), the volume being extracted and the season of the year (wet/dry), the resulting environmental impacts of producing a cubic meter of supplied water can be completely different. However, information on water supply systems is very limited in existing databases used in environmental assessment methods, such as Life Cycle Assessment (LCA) and Water Footprint, leading to a poor estimation of their impacts.

Conventional Life Cycle Inventory (LCI) databases such as ecoinvent (Wernet et al., 2016), GaBi 6 (Thinkstep, 2016) and Quantis Water Database (QWD) (QWD, 2015) provide a water balance of flows entering and leaving the product system (Section S1 in Supplementary Material (SI)). Water input flows account for water withdrawal from the environment, and water consumption is the total water withdrawal minus the total water released back to the 
river basin after use (ISO, 2014). However, LCI databases only include a few water sources and water treatment technologies without distinction of seasons and regions, although the ISO standard 14046 on water footprinting (ISO, 2014) recommends temporal and geographical differentiation of water flows. In terms of spatial and temporal resolution, current unit processes for water production in LCI databases represent a global annual average or a country annual average, with unknown origin if not defined by the LCA user and with no link to the water production technology applied (with the exception of tap water production in Quebec, see below). In particular, tap water, irrigation and cooling water uses are distinguished, although overall information is incomplete, both in terms of water origin and specific water production technologies.

To handle the diversity of water sources when the specific water origin is unknown, Hospido et al. (2013) introduced the concept of water mix for irrigation in LCA and provided a proof of concept for a river basin in Spain. They described a procedure to incorporate a water profile mix in the LCI for irrigation and evaluated the influence of that profile on the life cycle impact assessment (LCIA) level in terms of water consumption impacts. Their scenarios include the use of alternative water sources such as desalination or regenerated water to cover all irrigation demand. Energy use associated to the supply of each water resource type was also quantified and evaluated in terms of Global Warming Potential. Despite the interest of that model, it was only applied in one river basin and to one user (agriculture).

The tap water mix for Quebec (Lesage and Samson, 2013) (called "market for tap water" in the ecoinvent database (Wernet et al., 2016)) is an example of a practical implementation of the water mix in LCA. This mix differentiates between water sources, namely surface and groundwater, and the average of tap water production technologies used in Quebec, including the network and water losses during distribution. However, it only covers one region and one type of water use on an annual basis. Ono et al. (2015) developed an inventory database for 
111 water footprint based on input-output analysis of goods and services produced in Japan. While

112 different water sources and users have been considered in this approach, the geographic and

113 temporal differentiation is limited to annual average flows in Japan.

114 A summary of different approaches applied in LCA and other fields for the consideration of a

115 water mix in LCA is presented in Section S4 in SI. So far, examples in LCA only include

116 information on location and user type, whereas, seasonal variation and inventory related to

117 infrastructures and technologies (energy, materials, chemicals, etc.) are often not considered.

118 This paper proposes a consistent water supply mix (WSmix) model for implementation in

119 LCA, including harmonization of terminology and classification of water sources and users.

120 Integrating the WSmix in LCI databases provides local water mix profiles for processes in

121 LCA, depending on their location and with different spatial and temporal scales, which will

122 also allow LCIA methods to assess trade-offs between the various environmental impacts

123 associated to a given local mix. Besides that, it will also be useful for other fields related to

124 water sources management, supply and treatment technologies as well as water use and 125 consumption patterns.

\section{Problem definition and objectives}

127 The WSmix concept is relatively similar to the energy mix concept. The energy mix is a

128 worldwide standard model that determines how final energy consumption in a given

129 geographical region breaks down by primary energy sources (e.g. fossil fuels, nuclear energy,

130 waste and renewable energy) and by different uses (e.g. electricity generation, called

131 electricity mix, transportation, or heating of buildings). In the same manner, the WSmix is a

132 model describing how final water use for specific users (domestic, agriculture, industry) in a

133 given location and season breaks down by primary water (re)sources (e.g. surface water,

134 groundwater, precipitation) and by associated treatment and supply technologies (including 
135 infrastructure and energy consumed to extract, purify, deliver, heat/cool and treat water,

136 which is known as the water-energy nexus) (DOE, 2014).

137 However, the development of a worldwide WSmix for LCA raises several methodological

138 issues. First, current LCI databases only differentiate surface water, groundwater, seawater

139 and precipitation, but do not include alternative water sources such as inter-basin water

140 transfer or reused wastewater, which are gaining importance as part of adaptation strategies,

141 especially in arid and semi-arid countries. Furthermore, there is lack of harmonization

142 between existing LCI databases and LCIA models. Some models directly consider water

143 consumption, i.e. evaporation, transpiration, integration into a product, or release into a

144 different river basin or the sea (Mila i Canals et al., 2009; Pfister et al., 2009a), while others,

145 such as the models by Boulay et al. (2011) and WBCSD (2015) are based on the inventory of

146 water withdrawal and water released.

147 Another important limitation observed in LCI databases is the lack of information regarding

148 the required treatment technology or chain of technologies for a given water source to meet a

149 specific water demand (in terms of quantity and quality). The technologies used for water

150 withdrawal, water transportation and storage usually are not substantially different between

151 water sources. However, important differences in technologies for water treatment actually

152 exist, since they are designed for specific input and output quality standards (Meron et al.,

153 2016).

154 The goals of this paper are: 1) To develop a consistent WSmix framework to harmonize LCI

155 modelling practice of water supply systems ensuring consistent links with existing LCI

156 databases and LCIA methods. 2) To provide a first database of water source (or Origin) mixes

157 (WOmix) for different users at a global scale and a technological matrix linking water sources

158 to water production technologies in order to operationalize practical implementation of the 
WSmix in LCA studies. 3) To demonstrate the relevance of including the regional WSmix in

160 LCI databases for proper water-use impact assessment through an illustrative LCA case study.

\section{Methods and modelling}

162 This section describes the conceptual basis of the WSmix framework and discusses how to

163 implement it in practice based on both a WOmix database for different users and a

164 technological matrix linking water sources to water production technologies. Finally, the

165 overall WSmix framework is presented.

\subsection{Bases of the WSmix framework concept}

\subsubsection{System definition and boundaries}

168 The WSmix represents water supply systems, which are described as withdrawal, treatment,

169 and distribution of water from different water origins to water users (Lesage and Samson,

170 2013; Loubet et al., 2016; Meron et al., 2016; Vince et al., 2008). Therefore, it describes

171 water inputs to a process, while water outputs (i.e. release back to the ecosphere) are not

172 included. Consequently, the WSmix includes the combination of water origin, technologies of

173 water production and distribution for different water users at different spatial and temporal

174 scales (Figure 1). These technologies should be modelled with a life cycle perspective to

175 consider all impacts due to upstream activities (e.g. infrastructure, energy, chemicals).

176 Similarly to the energy mix and in particular the electricity mix in LCA (Frischknecht and

177 Tuchschmid, 2008), the system boundaries for the WSmix are defined from the water

178 resource withdrawal up to the delivery to the final user, excluding all processes during and

179 after the use phase. It includes all interactions between the ecosphere (environment) and the

180 technosphere (technical system), i.e. emissions and resource extractions. The only feedback 
181 from water users towards WSmix is the water quality that is required for each specific use and

182 that will define the required combination(s) of sources and technologies.

183

184

\subsubsection{Terminology and classification of the WSmix components}

The WSmix framework is consistent with existing data on water sources and water use, and also with LCI data, LCIA methods, and LCA software to be directly usable by LCA practitioners. At the same time, it is flexible enough to adapt to future LCIA methods and software developments.

A great variability of terminology and classification for water sources and water users was observed. For instance, when comparing two river basins in France for water sources, one has a water mix of four different, very aggregately defined origins, whereas the other has 10 different, detailed water origins (Adour-Garonne, 2013; Loire-Bretagne, 2013). The same holds true for water users when comparing data from two river basins in Spain, one distinguishing five water users (Guadalquivir, 2013) and the other eight (Miño-sil et al., 2007). More details are given in Sections S5 and S6 in the SI.

Therefore, harmonization is required prior to incorporation of such data into the WSmix. Bayart et al. (2010) developed a consistent classification of water sources and water users for LCA. The authors presented a set of freshwater categories according to the water origin and the water quality, where the quality can be determined with a functionality approach. According to Bayart et al. (2010), water is considered functional for a particular user if its quality parameters meet quality standards defined for a specific use. Boulay et al. (2011) operationalized the functionality approach (see Table S5 in SI) by using a list of 136 water quality parameters (physico-chemical characteristics, microbiology, organic matter, etc.) to define the functionality of water quality categories (i.e. its usability for different users) for three water origins, namely surface water, groundwater, and rain water. 
Despite the interest of this approach, it fails to consider that the same user may actually use different qualities of water in function of geographic and socio-economic conditions (Pradinaud et al., in review). Moreover, the number of parameters required for the best estimate of water quality does limit its applicability worldwide. Finally, the water source categories are too aggregated, with no distinction, for instance, between fossil and renewable 210 groundwater, as recommended by Kounina et al. (2013).

211 To propose a sound classification of water sources and users that addresses both LCA and water management requirements, a set of criteria has been defined:

1. The water source classification should be based on direct environmental relevance of each water source. The environmental relevance can be evaluated according to different aspects. The following parameters were considered in the WSmix classification:

a. Water renewability: Groundwater was classified into three sub-categories: alluvial, deep, and fossil groundwater, based on the different renewal rates of each water source, which is particularly low for the latter (GWF, 2014). In addition, the different levels of depth and consequently the energy required for pumping each type of groundwater were considered for the classification, as pump efficiency and type of power source vary (Pradeleix et al., 2015).

b. Water deprivation impacts: Regarding surface water, a classification into three sub-categories representing different water bodies is proposed: i) river, i.e. a water flow; ii) natural lake and wetland, i.e. standing water; and iii) springwater, i.e. the result of an aquifer saturated to the point that the water overflows into the land surface (Perlman, 2016). From an LCIA point of view, springwater is considered as withdrawn from surface water, thereby potentially 
contributing to surface water deprivation and impacts on surface waterdependent ecosystems.

c. Anthropogenic changes in the natural water flow of streams or rivers: Building of dams and off-river storage as well as diversion of flows with levees and other structures may contribute to the loss of biological diversity and ecological functions in aquatic and terrestrial ecosystems (NSW, 2013). Therefore, inter-basin water transfers and reservoirs (water retained in dams) were considered in the classification. They are both part of the proposed alternative water sources, and are included in the categories of external and artificial standing water sources, respectively (see Table S11 in SI). The origin of water transferred/stored was distinguished since the associated water treatment will be different. The main interest to include reservoirs in the WSmix are temporal considerations such as water storage in wet season for use during dry season (Scherer and Pfister, 2016).

2. Inclusion of non-conventional water sources, as another category of the proposed alternative water sources (see table S11 in SI). Water scarce countries are expected to progressively rely more on those sources to alleviate water scarcity. Five categories are distinguished: seawater, brackish/saline groundwater, domestic wastewater, harvested stormwater run-off, and directly harvested rainwater. Although, the last two have the same origin (rainwater), they have a different water quality since the first is generally more polluted (Wahaso, 2016). It is currently assumed that the use of alternative water sources have generally no impact on water scarcity (Hospido et al., 2013; Muñoz et al., 2010). However, they contribute to other impact categories due to the environmental impacts associated to the energy and technology for withdrawal/collection, treatment and distribution. 
3. Exclusive consideration of water uses related to water withdrawal (i.e. off-stream water use in LCA terminology (Bayart et al., (2010)). The water users were defined according to classifications used in local water management plans and suggested by other authors in addition to traditional large water consumption collectives (i.e. agriculture, cooling, and domestic). Sub-groups of water users have been included (for example, "agriculture" split into "irrigation", "livestock", "planted forestry", and "aquaculture (off-stream)") as the environmental impacts associated to the required water treatments may be different (see Section S6 in SI).

4. Maximum preservation of the level of detail considered in local water management plans and water agencies in terms of terminology and adherence to international standards such as those of the International Water Association (IWA) (IWA, 2015b), Aquastat (FAO, 2016), FAO (FAO, 2003) and ISO 14046 (ISO, 2014) (see Table S4 in SI).

\subsection{Water source mix (WOmix) database}

To facilitate implementation of the WSmix, this paper provides a worldwide database of

water source mixes per user at different spatial scales (country, river basin and sub-river basin) and, in a first stage, at annual temporal scale (Excel file in SI). Several data sources were analysed ranging from local water management plans (including direct contact with national or regional water agencies) to databases from international agencies such as Aquastat

273 (FAO, 2016) and Eurostat (European commission, 2016), and scientific literature (Sections S5 274 and S6 in SI).

275 For most countries, especially the developed ones, the data needed for a global and spatially 276 explicit WSmix are available. For instance, in Europe, data on water withdrawal for different 277 users at river-basin and sub-river-basin level are accessible through local water management 
plans via water agencies and national statistics. However, for some countries or regions, data

are available only at country scale, and in some cases no data were found (approximately half

of the countries in the world). For those cases, interpolation and aggregation of data from

to fill data gaps, based, for example, on socio-economic indicators and geographical location.

Data on temporal water withdrawal variability are available only for a few countries and river

basins. The vast majority of data is available with an annual resolution. For higher temporal

resolution, climate indicators and human activity patterns could be applied (although not done

in this study). Figure S7 in SI shows an example of temporal variability of water sources.

The current WOmix worldwide-regionalized database has information for 93 countries at national level, 18 countries at river basin level, and five countries at sub-river basin level, for

all water users and types of water sources (Figure 2). This database is the starting point to create WSmix LCI datasets.

\subsection{Overview of WSmix framework}

Figure 3 depicts the WSmix methodological framework that represents the water sources (surface, ground, sea, etc.) at the ecosphere level (environment) and all the technologies associated for withdrawal, transport, store and distribution of water at the technosphere level (technical system). Solid blue arrows (1b and 1c) represent the water flows entering from the ecosphere into the technical system and solid green arrows (1d and 1e) represent the water flows within the technosphere. After water use, water flows can be treated and reincorporated into the system to be reused after an additional treatment (3b) or returned to the environment after conventional waste water treatment ( $3 \mathrm{c}$ and $3 \mathrm{e}$ ). Dashed blue arrows represent water lost during transport and distribution ( $2 \mathrm{a}$ and $2 \mathrm{~b}$ ) while dashed light blue arrows represent water

301 consumed, i.e. water evaporated ( $2 \mathrm{c}, 3 \mathrm{~d}$ and $4 \mathrm{a})$ and the excess water transported that is 
released into the ocean (2d) (ISO, 2014). Further details about Figure 3 are given in Table S6 in SI.

The water technologies included in the WSmix are the technologies used for water production

(Figure 1). The environmental profile of each water technology is intrinsically linked to the local electricity mix.

Figure 4 shows the classification of water sources $\left(\mathrm{WO}_{\mathrm{x}}\right.$ and $\left.\mathrm{WO}_{\mathrm{y}}\right)$, water users $\left(\mathrm{WU}_{\mathrm{z}}\right)$, and associated technologies (WTec) for the WSmix. Depending on the type of water source and the specific user need, a treatment technology or set of technologies are proposed (see below). Six families of water technologies are regarded, all available in current LCI databases: deionisation, desalination, conventional treatment, advanced treatment, basic treatment and no treatment (Table S7 in SI). In doing so, the functionality principle (Bayart et al., (2010) and 313 Boulay et al., (2011)) is avoided.

314 For instance, Figure 4 shows that for public water uses, spring-water, alluvial, deep, and fossil 315 groundwater usually require a conventional treatment for groundwater. Eventually, specific 316 treatments for mineral compounds (e.g. $\mathrm{Fe}, \mathrm{Mn}, \mathrm{NH}_{4}, \mathrm{H}_{2} \mathrm{~S}$, etc.), depending on the 317 geochemistry, can be applied (Suez, 2016). However, for other water users, these water 318 sources may only need a basic treatment or even no treatment at all. Similarly, a conventional 319 treatment for surface water is often used for river, natural lakes, wetlands, and direct rainwater harvested (assuming that it undergoes the same treatment as a river) for public water uses, while other users may only need a basic treatment or no treatment.

322 Water from inter-basin water transfers and water from reservoirs are both special cases 323 regarding the type of treatment technology to apply. Depending on the origin of the 324 transported and stored water and the user needs, the treatment technology will differ. In case 325 of lack of information on water origin, a conservative assumption that the water transferred/stored is surface water, which usually has lower quality, has been adopted. 


\section{ACCEPTED MANUSCRIPT}

Seawater and brackish water are assumed to require the same treatment technologies for all

users. This is a simplification since a distinction between technologies in function of the feeding water stream and the technological evolution should be done (Subramani and Jacangelo, 2015).

331 For domestic waste water and harvested stormwater run-off, it is assumed that the water needs

332 specific treatment to be (re-)usable depending on the type of user and socio-economic 333 conditions. For instance, neither of both sources is considered to be used for public water uses. However, domestic waste water may be used for irrigation after advanced treatment in developed countries and without treatment in developing countries (WHO, 2012). Harvested stormwater run-off may often be heavily polluted (e.g. with hydrocarbons, pathogens, 337 pesticides, nitrates and other fertilizers). Therefore, it is assumed to be used only for 338 "manufacturing (raw water)" with a basic treatment and for irrigation and recreation after an 339 advanced treatment. Given the high cost and the frequently insufficient control of urban 340 planning globally, it is considered that the advanced treatment is only applied in 341 industrialized/developed countries (Parkinson and Mark, 2005).

342 Finally, the water distribution network (including water losses and evaporation) may vary

343 from country to country and between regions of each country due to local specificities (Farley 344 and Trow, 2003). In order to include it in the WSmix, the same relation as in the tap water 345 mix of Quebec (Lesage and Samson, 2013) has been used, where the distribution network is 346 calculated as a function of the yearly transported amount of water, the network's lifetime and 347 length. Detailed information on water losses and evaporation for WSmix is given in Section 348 S10 in SI.

349 As illustrated in Figure S8 in SI, the implementation of regionalized WSmix is based on the 350 water sources mix per user obtained from the WOmix database and the respective water 351 technologies. 
352 Further information regarding the description and harmonization of the water users and

353 sources, as well as aggregation to a more generic level needed in case of lack of information 354 (level 0 and level 1) are given in Tables S11 to S14 in SI.

\section{Illustrative case study}

\subsection{Description}

357 To demonstrate the relevance of including WSmix in LCI databases, an illustrative case study 358 has been conducted. A comparison of current practice and an application of the WSmix to assess the environmental impacts of potable water supply in two countries, Spain and France,

360 were performed. These two countries have been chosen as all relevant information is available and because they have contrasted water origins per user, leading to different associated treatment technologies. In addition, their electricity mixes are completely different (Figure 5) (IEA, 2017).

364 The functional unit (i.e. unit of reference for the comparison) was the supply of $1 \mathrm{~m}^{3}$ of 365 potable public water. The LCIA method used was ILCD 2011. Moreover, water deprivation 366 impacts were assessed with two scarcity indicators: the water stress index WSI (Pfister et al., 367 2009) and the AWARE index (Boulay et al., 2017). The Simapro 8 LCA software was used 368 for the assessment.

\subsection{System modelling}

370 To carry out the case study, two systems have been created in Simapro 8, i.e. WSmix of 371 potable public water in France and Spain, respectively. The starting point to build the WSmix 372 models was the volume and the proportion of different water sources withdrawal in each 373 country (see WOmix database in SI, Figure 5 and Table S18 in SI). The water elementary 374 flows and the processes for the water technologies were selected from the ecoinvent 3.2 
database using the "Allocation at the point of substitution" system model (Wernet et al., 2016). Since currently this database does not provide all the water elementary flows and treatment technologies required, some simplifications have been done. For example, the water production, conventional treatment". The same procedure was used for groundwater and sea water. The water supply network was also included and calculated considering specific variables of each country (length, lifetime and network product volume, see details in Table S18 in SI).

It is considered that the water evaporation from the whole water supply system is negligible (assuming that the use of open channels for water transportation is not significant in this particular case). Only water losses through leaks released to groundwater (i.e. not evaporated) were regarded. The respective electricity mix of each country was an input of each water technology used (Figure 5).

389 Finally, a comparison between both country-specific WSmix and the production of public 390 water supply using the "market for tap water, European average (RER)" has been done.

\subsection{Results and conclusions}

392 The LCA results show that the environmental impacts of the supply of $1 \mathrm{~m}^{3}$ of potable public

393 water from mixed sources vary widely and are highly dependent on the country. In addition,

394 there is a strong influence of the local electricity mix in the WSmix, which highlights the role 395 of the water-energy nexus. For instance, the difference of impacts (Figure 6) between France 396 and Spain is due to the composition of their respective electricity mixes, which is mainly 397 nuclear in France (contributing to ionizing radiation) and mainly fossil fuel-based in Spain 398 (contributing to climate change and other emission-based impacts). 
The comparison between the local WSmix for Spain, France and the average European market commonly used today in LCA studies shows great differences for all impact categories. This is explained by the fact that the European market is composed of an average

figure S4 in SI) and the European electricity mix (PRe-Consultants, 2016; Wernet et al.,

which is in line with results published by EEA (2007).

As a conclusion of the case study, the environmental impacts associated with different water

supply systems highly depend on the water sources mix, the technologies associated and the

local electricity mix, which is in line with previous studies (Hospido et al., 2013; Meron et al., using average processes (which is current practice in LCA) may lead to results far from the in LCI databases for proper water-use impact assessment.

\section{Discussion}

\subsection{Limitations and completeness}

419 The main assumptions and uncertainties of the WSmix framework are related to the water treatment technologies, water losses, and distribution networks. In particular, due to the lack

421 of country-specific water technology inventory data, water treatment technologies used are 422 those currently available in LCI databases. Although, the same range of technologies is used 
for all countries, a treatment level differentiation depending on the country's development

424 status has been introduced. Furthermore, it is assumed that the same water source type, such as "alluvial groundwater" and "deep groundwater", is subject to the same technology to meet

is based on this water belonging to the same water source type which therefore has similar technological treatment. This simplified approach is proposed for short-term implementation.

However, more data are needed on water treatment technologies by country/river basin and for different users, as compiled on a country and city basis for tap water production by Meron et al. (2016).

Regarding water losses and evaporation, due to lack of data, it is assumed that there are no differences between the types of network with respect to the type of use. However, more

434 research is needed to assess the influence of these differences on the WSmix, and also the 435 effect of urbanism, i.e. population density, on the network infrastructure, as shown by Roux et al. (2011) for the sewer network.

\subsection{Compatibility and requirements for implementation in LCA}

In most cases, LCA practitioners do not know the water origin and associated water treatment technology applied in their LCI processes, especially in the background product system

440 (Quinteiro et al., 2017). WSmix datasets will support LCA practitioners in their LCI modelling (see Section S17 for further information). Although, some water source types of

442 the WSmix are already included in LCI databases and assessed by LCIA methods, the WSmix 443 provides a higher detail not only in terms of water sources and water users, but also in terms 444 of spatial and temporal resolution. Therefore, some adaptations to make the WSmix 445 compatible with the currently most used LCI databases and to ensure seamless connection 446 with LCIA methods are required. Those adaptations may imply aggregation of water source 
types and water user categories as well as of spatial and temporal resolution, since current databases and software only allow annual and country differentiation. These aggregations rely on remaining at level 0 or 1 both for water sources and water users in order to avoid very long lists of datasets (Tables S11 and S12 in SI). Alternatively, data at level 2 could be integrated in LCA software through geographic information system (GIS) layers.

Compared to the electricity mix, the implementation of the WSmix in LCI databases may be more elaborate given all the variables associated with it. While an electricity mix is supplied with only a voltage differentiation (high voltage, low voltage and medium voltage), water quality requirements vary among water users, and therefore, embedded environmental impacts will be very different depending on the user, affecting both water sources and water production technologies. The apparent complexity of WSmix data collection and database implementation can be adapted to different levels of detail. Therefore, depending on the goal and scope of the study, available data and LCIA method used, the LCA practitioner will be able to choose the level of complexity required for the inventory.

Regarding LCIA methods for assessing water degradation and consumption impacts, current software allows for the calculation of water degradation impacts through the eutrophication, acidification, and ecotoxicity impact categories in a temporally and spatially generic way

464 (with the exception of openLCA which allows for regionalized LCIA calculation (Rodríguez and Greve, 2016)). For water consumption impact assessment, the most used scarcity indices, namely WSI (Pfister et al., 2009) and AWARE (Boulay et al., 2017) have been developed at software only at the country scale on an annual basis with distinction of agricultural, nonagricultural and unspecified uses for AWARE. However, none distinguishes between different water sources, meaning that all water origins (e.g. lake, river, and groundwater) 
using different sources does not translate into the impact score. In this context, considering methodologies than scarcity indices have different spatial coverage and temporal resolutions (Kounina et al., 2013), and require different levels of detail in terms of water sources (Table S2 in SI), which can all be considered by the WSmix framework.

Finally, the terminology used in the inventory flows should be consistent with that of the

482 classification step.

\section{Conclusion}

484 From a conceptual point of view, the proposed WSmix framework allows combining water 485 sources (e.g. surface, ground, sea) and related technologies to meet the needs of a user (e.g. domestic, irrigation, industry) at a specific time (season) and location (country and/or subriver basin) at a worldwide scale.

The case study highlights the relevance of including a WSmix in LCI databases for a consistent water-use related impact assessment in LCA. It will support LCA practitioners of different sectors (e.g. industry, energy, agriculture) to carry out a consistent environmental assessment of water use along the supply chain of their products and services. The WSmix will be useful in routine assessment of water-use related impacts, being just as straightforward as using the regional electricity supply mix in LCA.

494 From a practical point of view and based on the WSmix framework developed, a database of 
in SI). Data quality differs depending on the country but most countries, especially the

497 developed ones, have the data needed for a global and spatially explicit WSmix.

The WSmix framework and global regionalized WSmix database/maps also provide

499 interesting insights beyond the LCA scope to support strategic management of water sources

500 at any scale including the global scale. For instance, it is useful when quantitative data are

501 required to assess the (global) vulnerability of water sources or the future water supply

502 security in cities and densely populated regions.

503 Perspectives on the long-term implementation of WSmix rely on two main requirements: i) spatialization of LCA, and ii) forthcoming LCIA developments that differentiate water sources in order to account for differences in their impact profiles (Núñez et al., 2016).

The first requirement is to adapt a regionalised version of the WSmix in LCA software, with

507 specific values per sub-river-basin where the water use occurs. This can be done using GIS, 508 either by implementing an external GIS database connected to the LCI, or, at longer term, 509 with the integration of GIS within LCA software, as already done by openLCA (GreenDelta, 510 2016) and Brightway2 (Mutel, 2016)).

511 The second requirement is to make the WSmix compatible with future LCIA models for water 512 consumption impact assessment. These evolve towards models considering the 513 interconnections between water compartments within the river basin which are thus capable 514 of differentiating several water source compartments (Núñez et al., 2016). The flexible 515 WSmix framework has been designed bearing in mind such future requirements and is 516 already adapted to forthcoming generations of water use LCIA indicators. 
The authors acknowledge ANR, the Occitanie Region, ONEMA, its industrial partners (BRL,

"ELSA-PACT" (grant no. 13-CHIN-0005-01). The authors are members of the ELSA research group (Environmental Life Cycle and Sustainability Assessment, http://www.elsalca.org/) and thank all ELSA members for their advice. The authors also acknowledge Naime at Orleans University.

\section{References}

Adour-Garonne, 2013. Le bassin Adour-Garonne [WWW Document]. URL http://www.eauadour-garonne.fr/fr/informations-et-donnees/donnees-sur-l-eau.html (accessed 10.8.15).

Bayart, J.B., Bulle, C., Deschênes, L., Margni, M., Pfister, S., Vince, F., Koehler, A., 2010. A framework for assessing off-stream freshwater use in LCA. Int. J. Life Cycle Assess. 15, 439-453.

Boulay, A.-M., Bare, J., Benini, L., Berger, M., Lathuillière, M.J., Manzardo, A., Margni, M., Motoshita, M., Núñez, M., Pastor, A.V., Ridoutt, B., Oki, T., Worbe, S., Pfister, S., 2017. The WULCA consensus characterization model for water scarcity footprints: assessing impacts of water consumption based on available water remaining (AWARE). Int. J. Life Cycle Assess. doi:10.1007/s11367-017-1333-8

Boulay, A.M., Bouchard, C., Bulle, C., Deschênes, L., Margni, M., 2011. Categorizing water for LCA inventory. Int. J. Life Cycle Assess. 16, 639-651.

DOE, 2014. The Water-Energy Nexus: Challenges and Opportunities. Washington, USA.

540 EEA, 2007. Water scarcity. Copenhagen.

541 European commission, 2016. Eurostat database [WWW Document]. URL http://ec.europa.eu/eurostat (accessed 7.23.15). 
Author-produced version of the article published in Journal of Cleaner Production, 2018, N¹72, p.302-313.

The original publication is available at http://www.sciencedirect.com

Doi: 10.1016/j.jclepro.2017.10.135

\section{ACCEPTED MANUSCRIPT}

FAO,

2016.

AQUASTAT

[WWW

Document].

URL

http://www.fao.org/nr/water/aquastat/main/index.stm (accessed 1.19.16).

545

FAO, 2011. The state of the world's land and water resources for food and agricuture Managing systems at risk. New York, USA.

FAO, 2003. Review of world water resources by country [WWW Document]. URL http://www.fao.org/docrep/005/y4473e/y4473e00.htm\#Contents (accessed 9.8.15).

Farley, M., Trow, S., 2003. Losses in Water Distribution Networks. IWA publishing, UK.

Frischknecht, R., Tuchschmid, M., 2008. Energy Supply : Electricity Mix Updates.

GreenDelta, 2016. GreenDelta - Tools and consulting for sustainability [WWW Document]. URL www.openlca.org (accessed 5.6.16).

Guadalquivir, C. hidrologica del, 2013. Plan hidrografico de la demarcacion hidrografica del Gualdalquivir. Anejo nr 3. Usos Y Demandas De Agua.

GWF, 2014. Resources [WWW Document]. Glob. water Forum. URL http://www.globalwaterforum.org/about/contact-us/ (accessed 11.17.16).

Hemmeter, T., Martin, M., Olson, E., Tulloch, C., Burks, J., 2016. Urban Water Management Plan. Santa Clara Valley.

Hospido, A., Núñez, M., Antón, A., 2013. Irrigation mix: How to include water sources when assessing freshwater consumption impacts associated to crops. Int. J. Life Cycle Assess. $18,881-890$.

IEA, 2017. Monthly electricity statistics. Paris, France.

ISO, 2014. ISO 14046:2014 (E) Environmental management. Water footprint - principles, requirements and guidelines.

IWA, 2015a. Alternative Water Resources: A Review of Concepts, Solutions and Experiences. London, UK.

IWA, 2015b. IWA Waterwiki [WWW Document]. URL http://www.iwa-network.org/ (accessed 6.20.15).

Kounina, A., Margni, M., Bayart, J.-B., Boulay, A.-M., Berger, M., Bulle, C., Frischknecht, R., Koehler, A., Milà i Canals, L., Motoshita, M., Núñez, M., Peters, G., Pfister, S., Ridoutt, B., Zelm, R., Verones, F., Humbert, S., 2013. Review of methods addressing freshwater use in life cycle inventory and impact assessment. Int. J. Life Cycle Assess. 
18, 707-721.

Lesage, P., Samson, R., 2013. The Quebec Life Cycle Inventory Database Project: Using the ecoinvent database to generate, review, integrate, and host regional LCI data. Int. J. Life Cycle Assess. 21, 1282-1289.

Loire-Bretagne, 2013. Le bassin Loire-Bretagne [WWW Document]. URL http://www.eauloire-bretagne.fr/informations_et_donnees/donnees_brutes/eau_potable (accessed 7.30.15).

Loubet, P., Roux, P., Bellon-Maurel, V., 2016. WaLA, a versatile model for the life cycle assessment of urban water systems: Formalism and framework for a modular approach. Water Res. 88, 69-82.

Meron, N., Blass, V., Garb, Y., Kahane, Y., Thoma, G., 2016. Why going beyond standard LCI databases is important: lessons from a meta-analysis of potable water supply system LCAs. Int. J. Life Cycle Assess. 21, 1-14.

Mila i Canals, L., Chenoweth, J., Chapagain, A., Orr, S., Anton, A., Clift, R., 2009. Assessing freshwater use impacts in LCA: Part I-inventory modelling and characterisation factors for the main impact pathways. Int. J. Life Cycle Assess. 14, 28-42.

Miño-sil, D.H.D.E.L., Hidrológico, P., Demarcación, D.E.L.A., Del, H., 2007. Anejo iii usos y demandas de agua.

Muñoz, I., Milà-I-Canals, L., Fernández-Alba, A.R., 2010. Life Cycle Assessment of Water Supply Plans in Mediterranean Spain: The Ebro River Transfer Versus the AGUA Programme. J. Ind. Ecol. 14, 902-918.

Mutel, C., 2016. Brightway 2 [WWW Document]. URL https://brightwaylca.org/ (accessed 12.12.16).

NSW, 2013. Alteration to the natural flow regimes of rivers, streams, floodplains \& wetlands - key threatening process listing [WWW Document]. Off. Environ. Herit. URL http://www.environment.nsw.gov.au/threatenedspecies/AlterationNaturalFlowKTPListin g.htm (accessed 1.27.17).

Núñez, M., Roux, P., Bare, J., Boulay, A., Bulle, C., Lathuillière, M., Margni, M., Pfister, S., Verones, F., Rosenbaum, R.K., 2016. Including the hydrological cycle through a multimedia assessment of water flows in water consumption LCIA modelling, in: 22nd LCA Case Study Symposium, 20-22 September. Montpellier, France. 
Ono, Y., Motoshita, M., Itsubo, N., 2015. Development of water footprint inventory database on Japanese goods and services distinguishing the types of water resources and the forms of water uses based on input-output analysis. Int. J. Life Cycle Assess. 20, 1456-1467.

Parkinson, J., Mark, O., 2005. Urban Stormwater Management in Developing Countries. IWA publishing, London, UK.

Perlman, H., 2016. Springs - The Water Cycle [WWW Document]. URL http://water.usgs.gov/edu/watercyclesprings.html (accessed 11.28.16).

Pfister, S., Koehler, A., Hellweg, S., 2009. Assessing the environmental impacts of freshwater consumption in LCA. Environ. Sci. Technol. 43, 4098-4104.

Pradeleix, L., Roux, P., Bouarfa, S., Jaouani, B., Lili-chabaane, Z., Bellon-maurel, V., 2015. Environmental Impacts of Contrasted Groundwater Pumping Systems Assessed By Life Cycle Assessment Methodology : Contribution To the Water - Energy Nexus Study $\dagger$. Irrig. Drain. Syst. 138, 124-138.

PRe-Consultants, 2016. Simapro - Putting the metrics behind sustainability.

Quinteiro, P., Ridoutt, B., Arroja, L., Dias, A.C., 2017. Identification of methodological challenges remaining in the assessment of a water scarcity footprint : a review. Int J Life Cycle Assess. doi:10.1007/s11367-017-1304-0

QWD, 2015. Quantis Water Database [WWW Document]. URL http://www.quantisintl.com/en/ (accessed 3.9.15).

Rodríguez, C., Greve, S., 2016. Regionalized LCIA in openLCA. Berlin, Germany.

Roux, P., Mur, I., Risch, E., Boutin, C., 2011. Urban planning of sewer infrastructure: Impact of population density and land topography on environmental performances of wastewater treatment systems, in: LCM. Berlin, Germany.

Scherer, L., Pfister, S., 2016. Global water footprint assessment of hydropower. Renew. Energy 99, 711-720.

Stokes, J.R., Horvath, A., 2009. Energy and Air Emission Effects of Water Supply. Environ. Sci. Technol. 43, 2680-2687.

Subramani, A., Jacangelo, J.G., 2015. Emerging desalination technologies for water treatment: A critical review. Water Res. 75, 164-187.

Suez, 2016. Suez Degremont Water Handbook [WWW Document]. URL 

https://www.suezwaterhandbook.com/ (accessed 2.16.17).

Thinkstep, 2016. Thinkstep database (GaBi LCA software).

Vince, F., Aoustin, E., Bréant, P., Marechal, F., 2008. LCA tool for the environmental evaluation of potable water production. Desalination 220, 37-56. doi:10.1016/j.desal.2007.01.021

Wahaso, 2016. Stormwater Harvesting Systems [WWW Document]. URL

641 technologies used in the WSmix http://www.wbcsd.org Assess. 21, 1218-1230. Sci. Eng. 8, 263-272.

\section{Figures} http://wahaso.com/stormwater_harvesting.php (accessed 2.23.17).

WBSCD, 2015. The WBSCD Global Water Tool [WWW Document]. Geneva, Switz. URL

Wernet, G., Bauer, C., Steubing, B., Reinhard, J., Moreno-Ruiz, E., Weidema, B., 2016. The ecoinvent database version 3 (part I): overview and methodology. Int. J. Life Cycle

WHO, 2012. Directives OMS pour l'utilisation sans risque des eaux usées, des excreta et des eaux ménagères. Genève, Switzerland.

WWDR4, 2012. Managing Water Under Uncertainty and Risk. Paris, France.

Zhou, Q., Wang, W., Pang, Y., Zhou, Z., Luo, H., 2015. Temporal and spatial distribution characteristics of water resources in Guangdong Province based on a cloud model. Water

Figure 1 Schematic representation of the water supply mix (WSmix) concept

Figure 2 Countries covered by WOmix per user database

Figure 3 Methodological framework of water supply mix

Figure 4 Correspondence between water source, water users, and water treatment

Figure 5 WSmix applied to France and Spain 
Author-produced version of the article published in Journal of Cleaner Production, 2018, N¹72, p.302-313.

The original publication is available at http://www.sciencedirect.com

Doi: 10.1016/j.jclepro.2017.10.135

\section{ACCEPTED MANUSCRIPT}

660 Figure 6 WSmix environmental impacts associated to the production of $1 \mathrm{~m}^{3}$ of potable public

661 water in France and Spain compared to current market for tap water in ecoinvent

662

663

664

665 
Author-produced version of the article published in Journal of Cleaner Production, 2018, N¹72, p.302-313.

The original publication is available at http://www.sciencedirect.com

Doi: $10.1016 /$ i.jclepro.2017.10.135

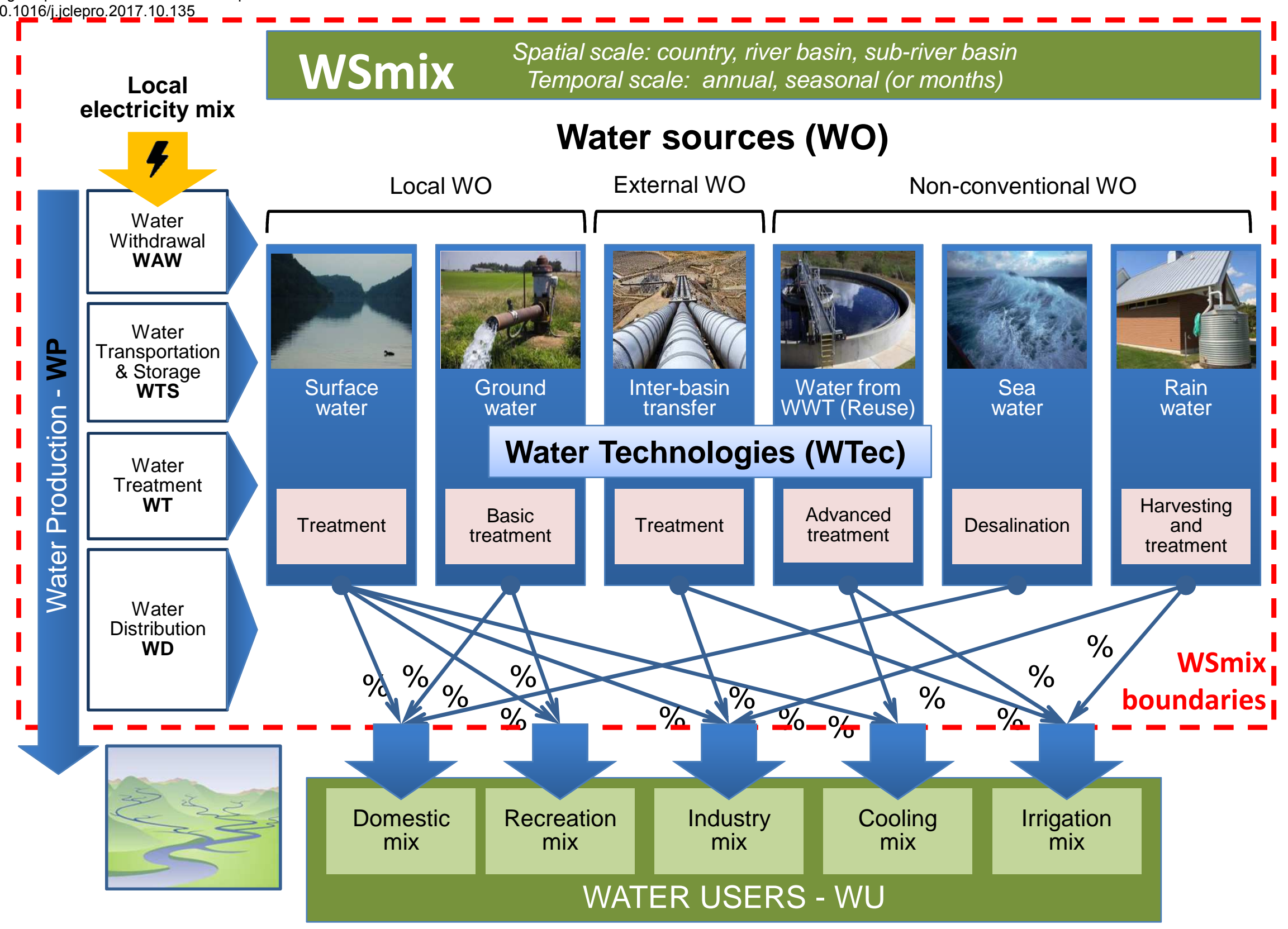

Figure 1 Schematic representation of the water supply mix (WSmix) concept 
Author-produced version of the article published in Journal of Cleaner Production, 2018, N¹72, p.302-313.

The original publication is available at http://www.sciencedirect.com

Doi: 10.1016/j.jclepro.2017.10.135

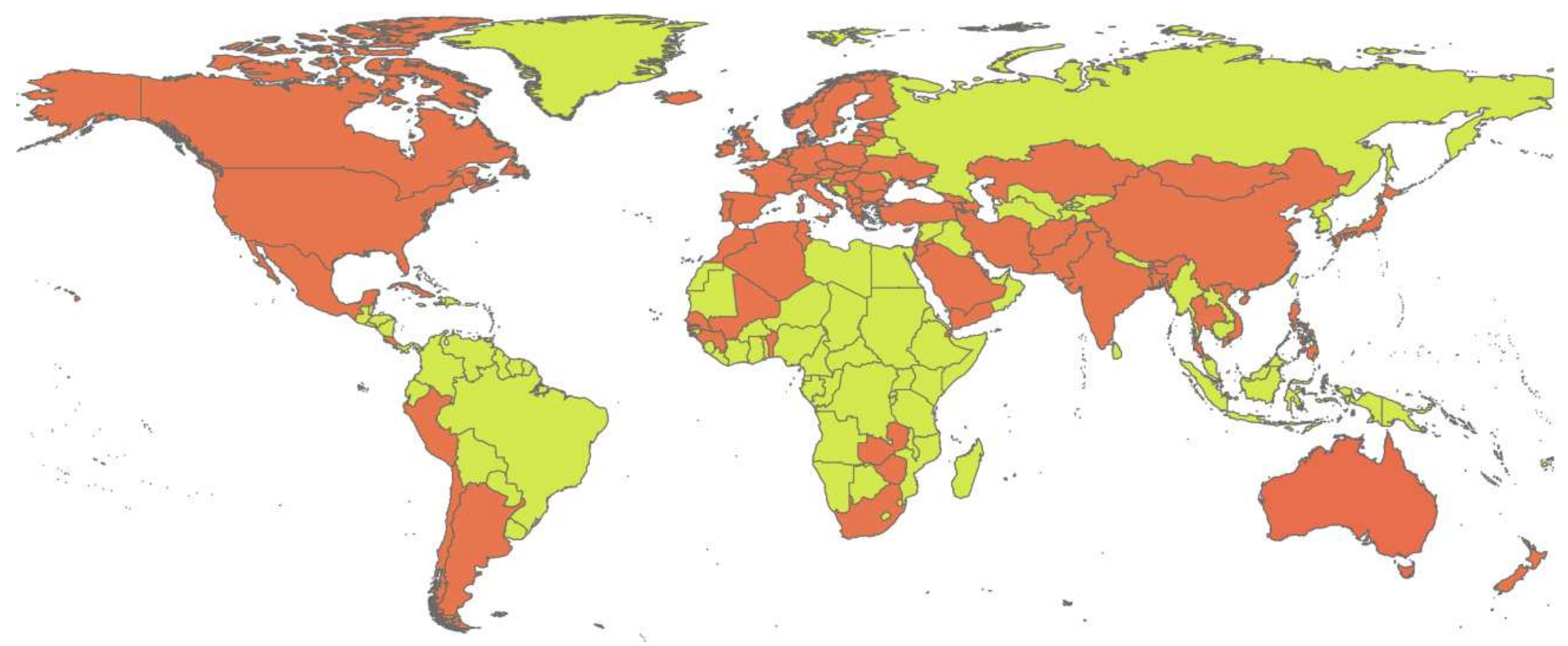

Countries covered by WOmix per use database

Countries not covered yet

Figure 2 Countries covered by WOmix per use database 
Author-produced version of the article published in Journal of Cleaner Production, 2018, N¹72, p.302-313.

The original publication is available at http://www.sciencedirect.com

Doi: 10.1016/j.jclepro.2017.10.135

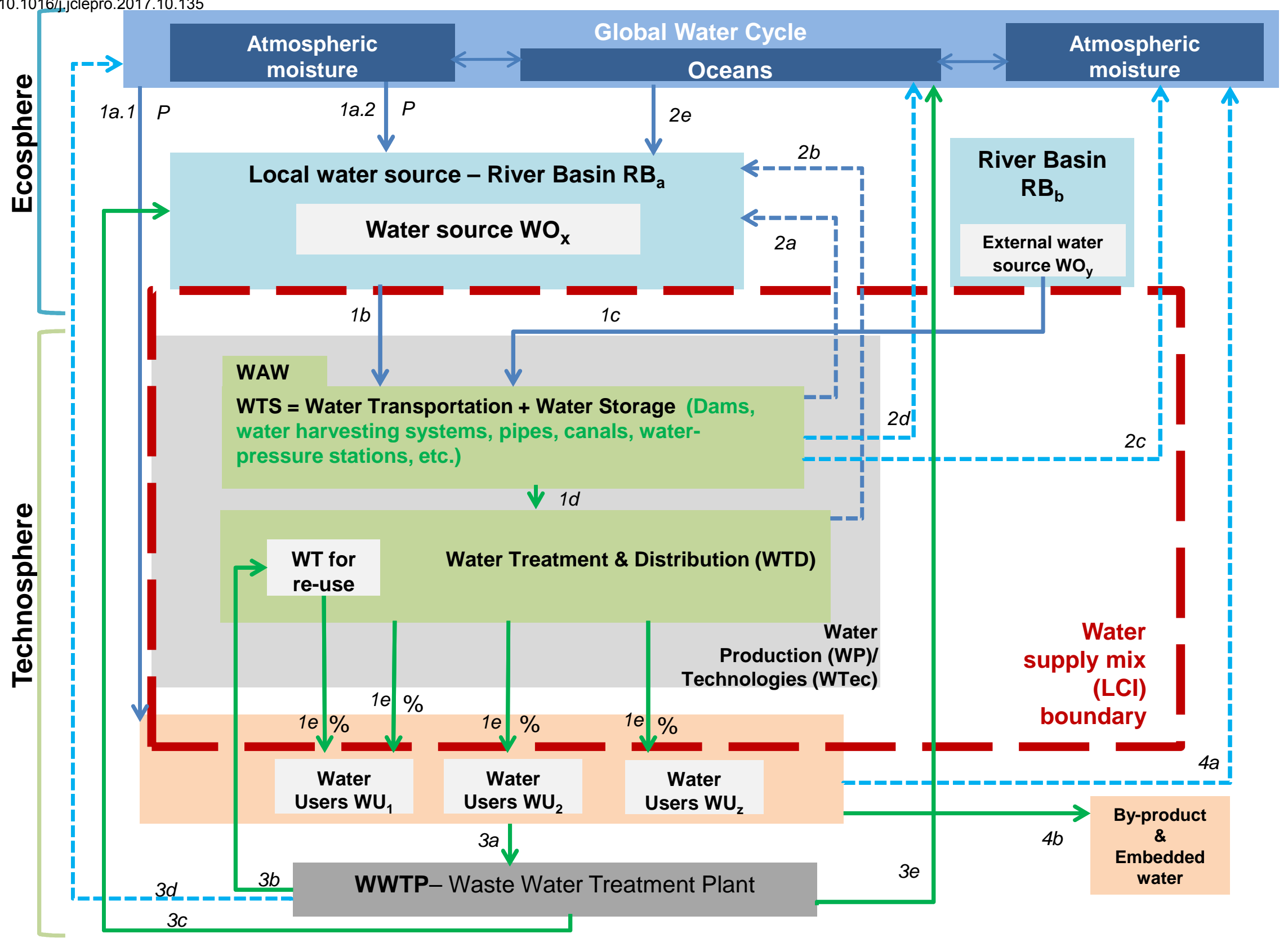

Figure 3 Methodological framework of water supply mix 


\section{Legend}

$\longrightarrow$ Water source flow from ecosphere

Water source flow from technosphere

Water evaporation to global water cycle and water released into ocean

Water losses during transportation and distribution

\section{Water flows}

1a.1= Direct precipitation supply to the user (e.g. natural irrigation)

1a.2= Precipitation into the water bodies of the river basin (RB)

$1 b=$ Water source flow from the ecosphere and transported and possibly stored before treatment and

\section{Indices}

distribution to the user

$1 c=$ Water source flow transferred from a neighboring river basin

$1 d=$ Water source flow coming from water transportation \& storage (WTS) to water treatment and distribution (WTD)

$1 e=$ Water source flow treated and supplied to the user

$2 a=$ Local water losses due to transportation

$2 b=$ Local water losses due to the distribution network

$2 c=$ Evaporation to the atmosphere

$2 d=$ Excess water from transportation which is released into the ocean

$2 e=$ Water source flow from the ocean

$3 a=$ Water source flow to the water treatment plant after use

$3 b=$ Reused wastewater

$3 c=$ Water released into the local environment after treatment

$3 d$ and $4 a=$ Evaporation to the atmosphere

$3 e=$ Water released into the ocean after treatment

$4 b=B y$-products (embedded water) obtain from the water activities

Figure 3 Methodological framework of water supply mix 
Author-produced version of the article published in Journal of Cleaner Production, 2018 №172,

The original publication is available at http://www.sciencedirect.com

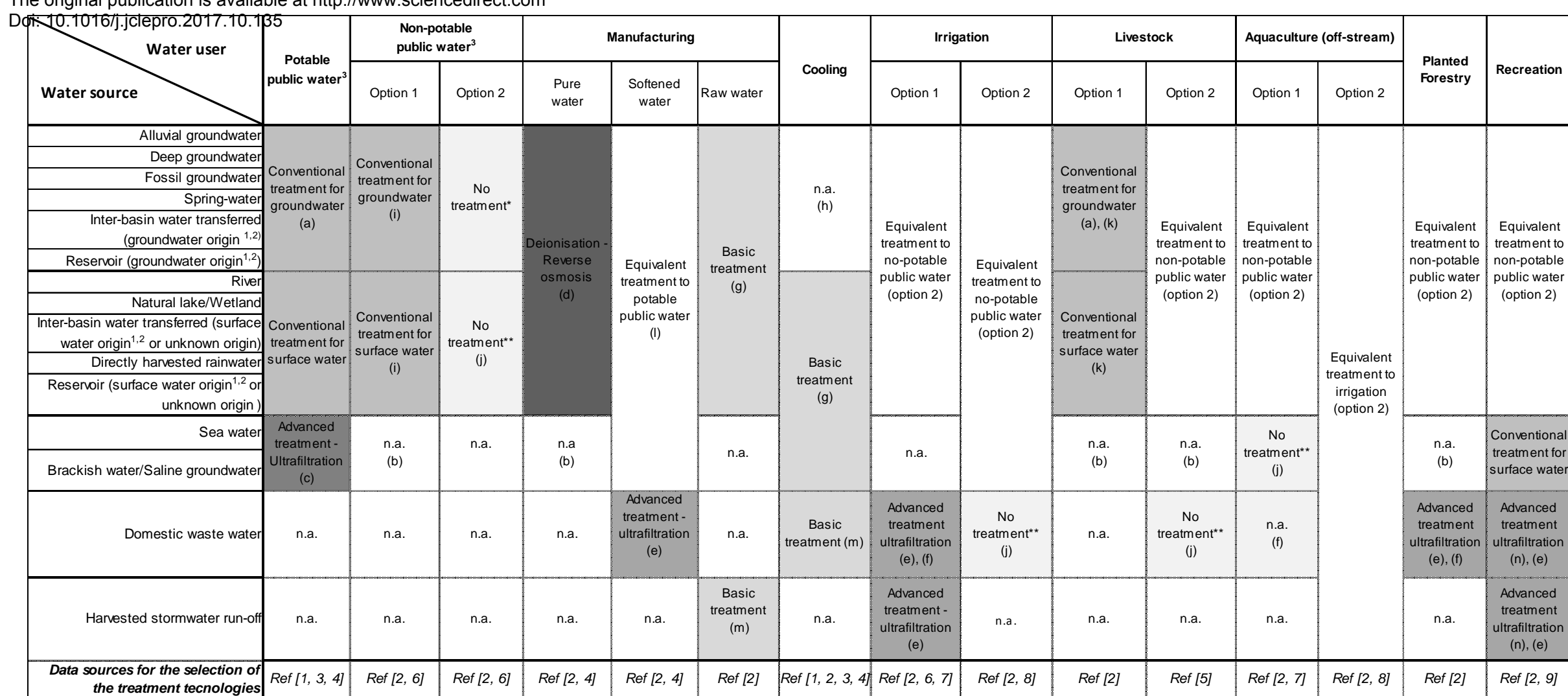

Ref. [1] Meron et al. (2016), Ref. [2] Based on expert judgment based on knowledge and experience of the authors and processes available in LCI databases, Ref. [3] Hydranet (2016), Ref. [4] Suez (2016), Ref. [5] IWMI (2010), Ref. [6] WHO (2016), Ref. [7] FAO (2016), Ref. [8] WHO (2012), Ref. [9] NSW (2006)

No treatment

Basic treatment

Conventional treatment

Equivalent treatments

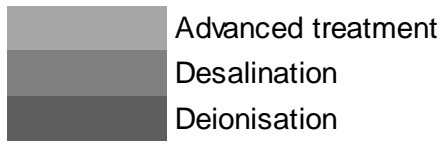

Deionisation
*Option 1 and option 2 allows a differentiation for developed and developing country (see more details in SI, table S12)

Note: see comments from (a) to (n), indices ${ }^{1,2,3}$ and ${ }^{*},{ }^{* *}$ in Table S15 in SI

Figure 4 Correspondence between water source, water users, and water treatment technologies used in the WSmix 
Author-produced version of the article published in Journal of Cleaner Production, 2018, N¹72, p.302-313.

The original publication is available at http://www.sciencedirect.com

Doi: 10.1016/j.jclepro.2017.10.135
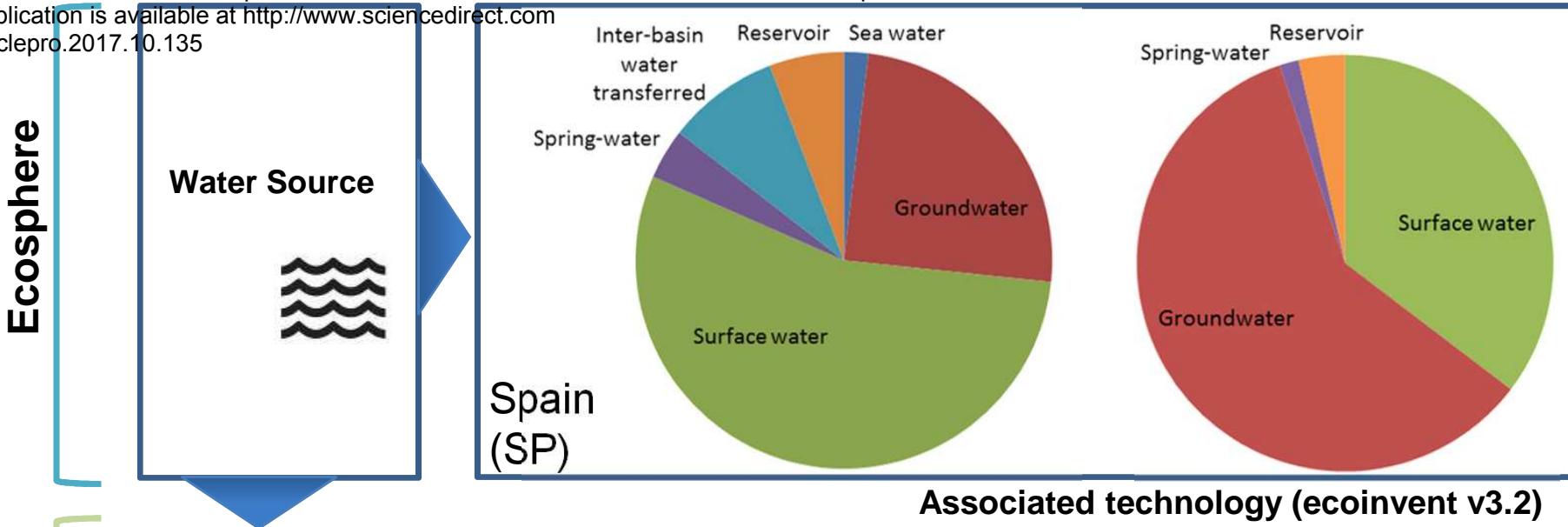

France
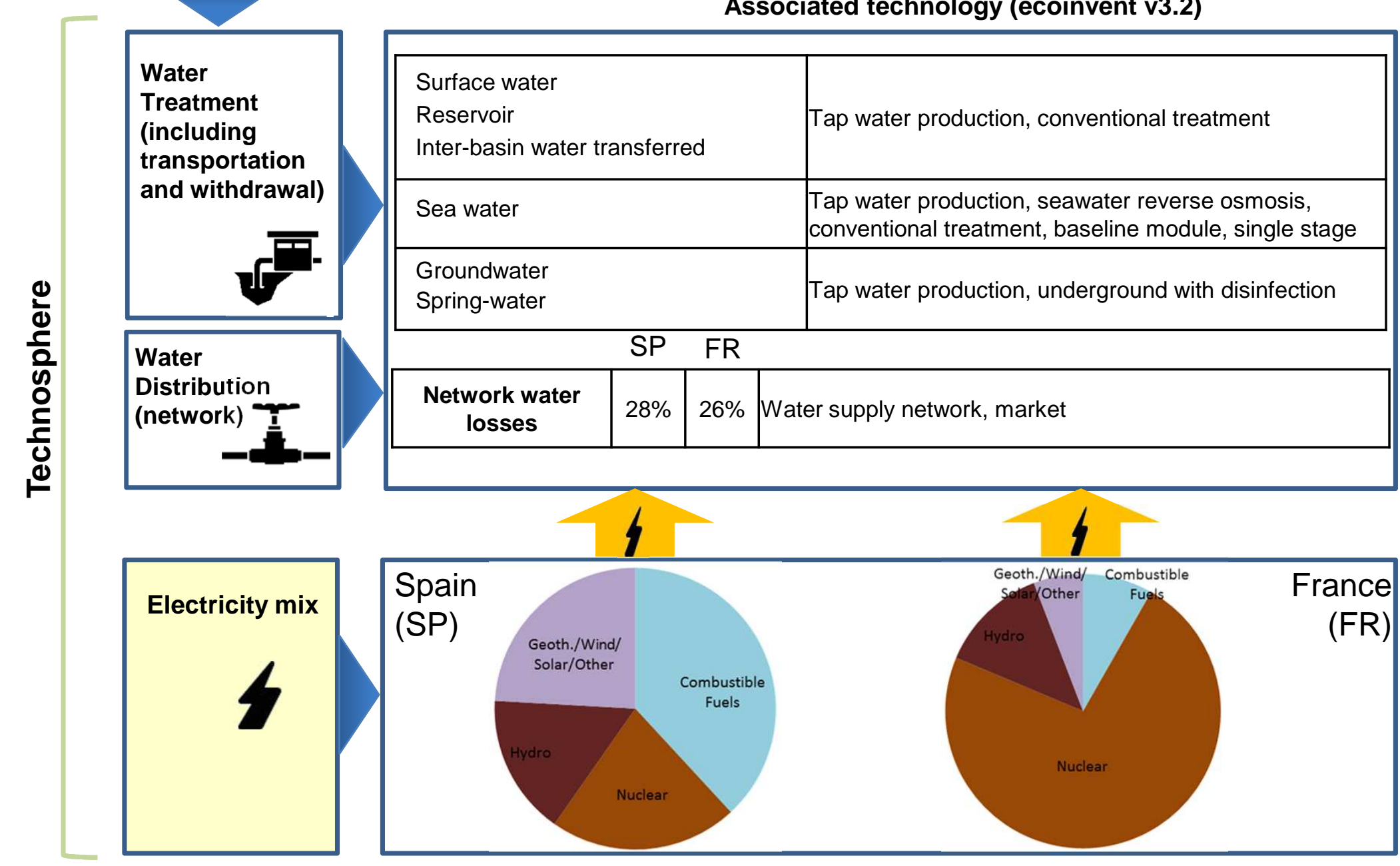

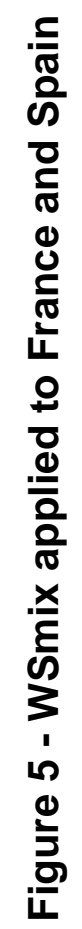



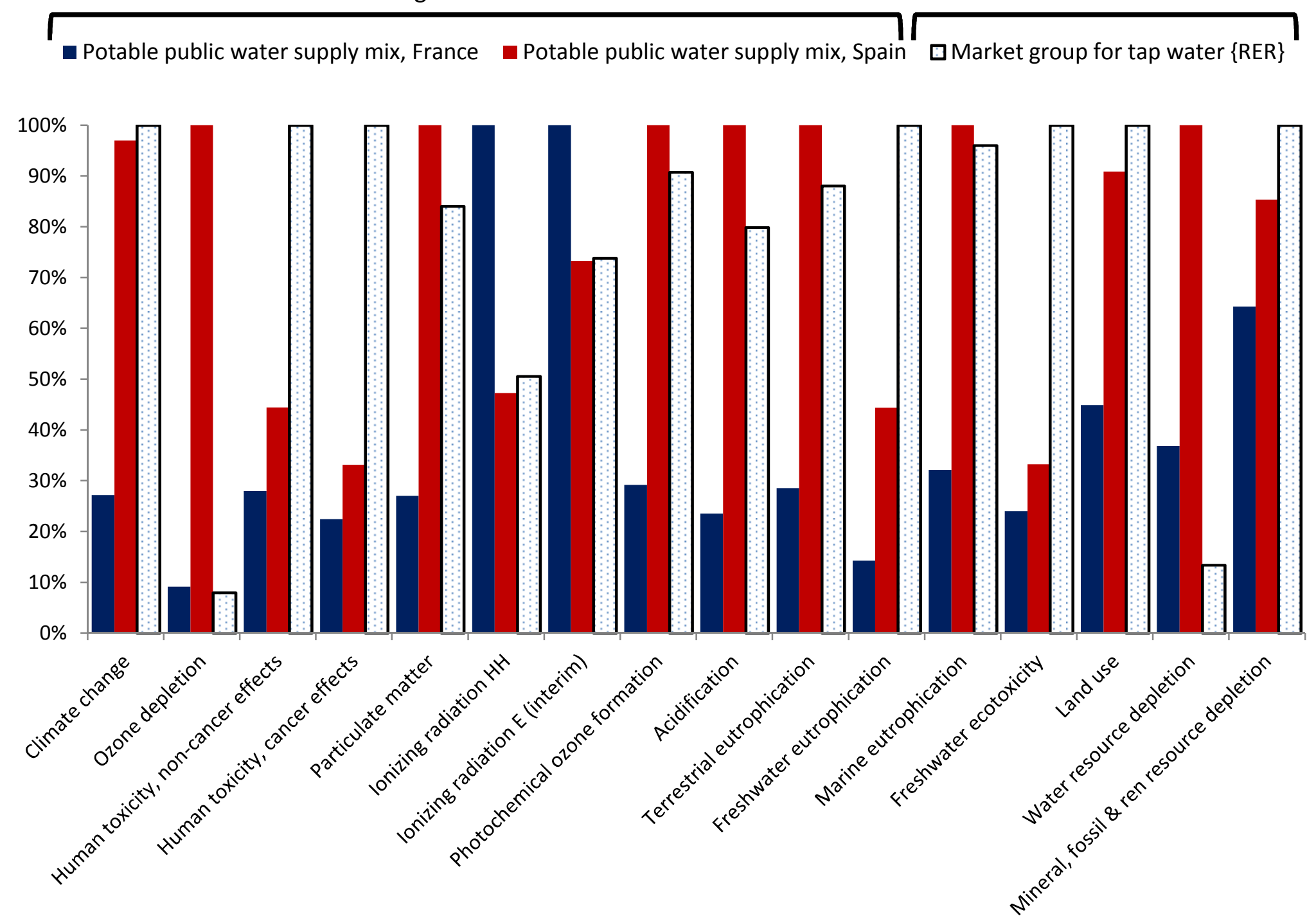

Figure 6 - WSmix environmental impacts associated to the production of $1 \mathrm{~m}^{3}$ of potable public water in France and Spain compared to current market for tap water in ecoinvent 


\section{Highlights:}

- A Water Supply mix (WSmix), in analogy with the electricity mix, is framed

- The WSmix is the regional combination of water sources per water user worldwide

- A water source mix database at country \& (sub) river-basin is built per water user

- Environmental impacts of WSmix also depend on electricity mix (water-energy nexus)

- The WSmix will allow routine assessment of water-use related impacts in LCA 